\title{
EM 14 - Bubbleless Gas Transfer Technology for the In Situ Remediation of Chlorinated Hydrocarbons
}

\author{
Semi-Annual Report \\ April 1 - September 30, 1998
}

\author{
By \\ Marc D. Kurz; John R. Gallagher
}

Work Performed Under Contract No.: DE-FC21-94MC31388

For

U.S. Department of Energy

Office of Fossil Energy

Federal Energy Technology Center

P.O. Box 880

Morgantown, West Virginia 26507-0880

By

Energy \& Environmental Research Center

University of North Dakota

P.O. Box 9018

Grand Forks, North Dakota 58202-9018 


\section{Disclaimer}

This report was prepared as an account of work sponsored by an agency of the United States Government. Neither the United States Government nor any agency thereof, nor any of their employees, makes any warranty, express or implied, or assumes any legal liability or responsibility for the accuracy, completeness, or usefulness of any information, apparatus, product, or process disclosed, or represents that its use would not infringe privately owed rights. Reference herein to any specific commercial product, process, or service by trade name, trademark, manufacturer, or otherwise does not necessarily constitute or imply its endorsement, recommendation, or favoring by the United States Government or any agency thereof. The views and opinions of authors expressed herein do not necessarily state or reflect those of the United States Government or any agency thereof. 


\section{DISCLAIMER}

Portions of this document may be illegible in electronic image products. Images are produced from the best available original document. 


\section{TABLE OF CONTENTS}

LIST OF FIGURES $\ldots \ldots \ldots \ldots \ldots \ldots \ldots \ldots \ldots \ldots \ldots \ldots \ldots \ldots \ldots \ldots \ldots \ldots \ldots$

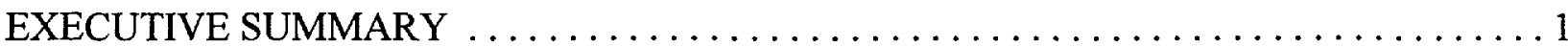

$1.0 \quad$ INTRODUCTION/BACKGROUND $\ldots \ldots \ldots \ldots \ldots \ldots \ldots \ldots \ldots \ldots \ldots \ldots \ldots$

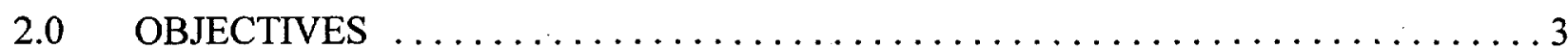

3.0 ACCOMPLISHMENTS/WORK PERFORMED $\ldots \ldots \ldots \ldots \ldots \ldots \ldots \ldots \ldots$

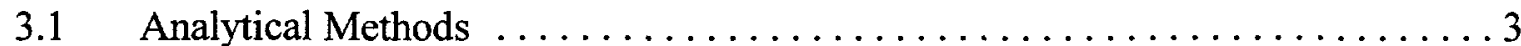

3.1.1 Gas Chromatography - Electron Capture Method .............. 3

3.1.2 Gas Chromatography - Flame Ionization Method ............. 4

3.1.3 Aquifer Simulators . . . . . . . . . . . . . . . . . . . . . . . 4

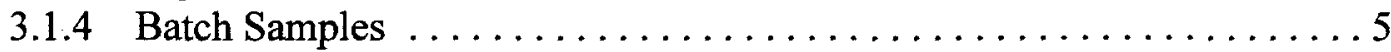

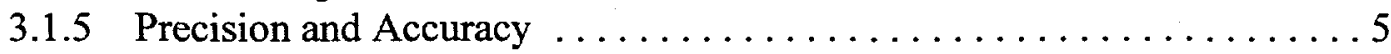

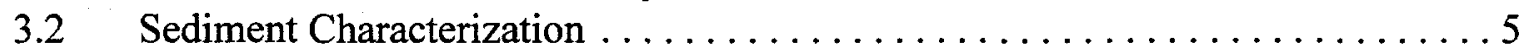

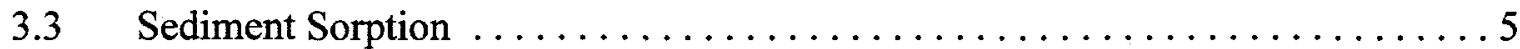

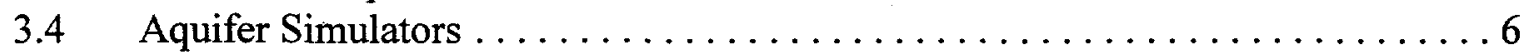

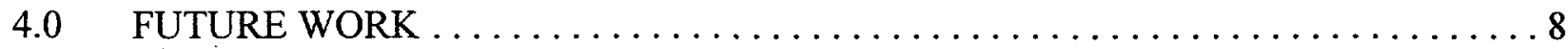

\section{LIST OF FIGURES}

1 Example calibration curve for PCE using TCP as the internal standard and GC with electron capture detection. . . . . . . . . . . . . . . . . . . . . . . . . . . 4

2 Sorption or partitioning of PCE into sediment from Roeder, North Dakota. . . . . . . . . . 6

3 Comparison of effluent PCE concentrations in the treated and untreated aquifer simulators at the higher PCE loading $(100 \mathrm{mg} / \mathrm{L}$ in the influent $) \ldots \ldots \ldots \ldots \ldots \ldots$

4 Influent and effluent PCE concentrations from the flow-through aquifer simulator using hydrogen-mediated biological treatment during pseudo steady state. $\ldots \ldots \ldots \ldots \ldots \ldots 8$ 


\section{EM 14 - BUBBLELESS GAS TRANSFER TECHNOLOGY FOR THE IN SITU REMEDIATION OF CHLORINATED HYDROCARBONS}

\section{EXECUTIVE SUMMARY}

Highly chlorinated hydrocarbons such as tetrachloroethylene (PCE) are among the most difficult to remediate in situ. Moreover, chlorinated hydrocarbons such as PCE are common at many industrial and commercial sites, including many of those owned and managed by the U.S. Department of Energy (DOE). Biological technologies for in situ remediation are often desirable because of their low cost. However, until recently there were no biological technologies for the highly chlorinated hydrocarbons, but recent discovery and understanding have yielded the reductive dechlorination process. Reductive dechlorination is a process where many bacteria, in the absence of oxygen and some other electron acceptors (nitrate), will use the chlorinated hydrocarbon as an electron acceptor, resulting in replacement of the chlorine with hydrogen. Even with the use of the biological reductive dechlorination technology, success is not guaranteed. The site must be engineered such that other electron acceptors are absent and electron donors are present. Among these key electron donors is hydrogen. Hydrogen is generated during anaerobic catabolism, but only in low concentrations. In addition, hydrogen may be metabolized without using it in reductive dechlorination. It has proven difficult to achieve significant hydrogen concentrations in the subsurface.

Bubbleless gas transfer technology has a track record of adding gases to water efficiently. This project was initiated to investigate the technical feasibility of using hydrogen addition to aquifers contaminated with PCE and similar chlorinated hydrocarbons as a means of supplying electrons for reductive dechlorination. Previous work has shown the rates, performance, and other key data on gas transfer using the bubbleless technology. This work focused on testing whether exogenous hydrogen can be used to promote the dechlorination process.

To test the use of exogenously supplied hydrogen to fuel reductive dechlorination, aquifer simulators were constructed using borosilicate glass and Teflon ${ }^{\mathrm{TM}}$ fittings. These columns were operated in closed loops and later in a flow-through mode. Early data confirmed that PCE at concentrations above $10 \mathrm{mg} / \mathrm{L}$ was toxic to reductive dechlorinating microbes. Later studies conducted in the flow-through mode at a mean PCE concentration of $1400 \mathrm{ppb}$ showed reductions in the simulator to about $840 \mathrm{ppb}$, for a total of $570 \mathrm{ppb}$ removed in the simulator. This represents a significant improvement over what might be expected through natural attenuation alone (no additions) and shows that exogenously supplied hydrogen can stimulate the removal of PCE in situ.

\subsection{INTRODUCTION/BACKGROUND}

Chlorinated hydrocarbons have been widely distributed in the environment because of their chemical and physical properties and the formerly widespread use of these compounds. In fact, chlorinated hydrocarbons such as trichloroethylene (TCE), tetrachloroethylene, perchloroethylene 
(PCE), chloroform (CF), and others are the most common pollutants in groundwater. Moreover, these pollutants represent one of the most important classes of pollutants at DOE and Department of Defense sites. While there are surface-based remediation technologies such as air stripping and carbon adsorption that are applicable to these pollutants, these technologies are expensive and do not remediate the subsurface effectively. Subsurface contamination is difficult to address because of the poor solubility of the chlorinated hydrocarbons and their strong tendency to sorb to surfaces. In situ remediation technologies operate where the pollution occurs and do not rely on desorption and transport to the surface.

Most in situ remediation technologies for the chlorinated hydrocarbons rely on biological destruction, directly or indirectly. Biological methods can be used in virtually any aquifer, but are limited by the ability to supply nutrients, electron donors, electron acceptors, or cosubstrates.

The most recalcitrant groups of chlorinated hydrocarbons are the highly chlorinated aliphatics such as PCE and carbon tetrachloride. These compounds are not metabolized by microorganisms that can degrade TCE and other less-chlorinated compounds. However, they can be degraded by a process known as reductive dehalogenation. Reductive dehalogenation is mediated by microorganisms or their biomolecules and results in a replacement of a halogen such as chlorine with hydrogen. In essence, the microorganisms use the chlorinated hydrocarbon as an electron acceptor. Thus, the appropriate conditions to stimulate reductive dehalogenation are anaerobic conditions with a good supply of electron donors and a paucity of electron acceptors. Reductive dehalogenation can be stimulated by the addition of organic compounds to supply electrons. However, many microorganisms can degrade these organic substrates without affecting the chlorinated hydrocarbons. The addition of hydrogen gas supplies electrons without supplying carbon, resulting in less nonspecific growth and metabolism.

In order to induce active dehalogenation of chlorinated hydrocarbons in a typical aquifer, the zone of contamination must be converted to reducing conditions and excess electron donors supplied. The addition of hydrogen gas can remove oxygen from the aquifer, as it is readily metabolized by a variety of common microorganisms. Hydrogenase enzymes that can strip electrons from hydrogen are widespread among anaerobic and many aerobic bacteria. Once the aquifer is reduced by the removal of oxygen, the hydrogen will supply the reducing equivalents necessary for reductive dehalogenation.

To accomplish hydrogen-mediated reductive dehalogenation, efficient mechanisms are needed to add hydrogen to zones of contamination. Bubbleless gas-transfer technology allows for the direct dissolution of gases into water through modules containing sealed, hollow, gas-permeable fibers filled with pure gases under pressure. The diameter of the fibers ranges from 200 to 400 microns, providing a large surface area in the module. The gas diffuses across the fiber walls and dissolves directly into the water surrounding and flowing past the outside surface of the fiber membrane.

The chief advantage of this technology over other gas dissolution technologies is that the gas is dissolved without the generation of bubbles, increasing gas-transfer efficiency and preventing off-site migration of gases and clogging of the aquifer with bubbles. Additionally, in 
other gas-transfer techniques, the excess gases supplied to the aquifer will generate offgas that may require treatment.

The factors limiting the amount of gas that can be dissolved into water are Henry's Law constant and the aqueous solubilities of the gases. The mass flux of the gases into the groundwater determines the rate of bioremediation, since biological demand for the gas can exceed the water solubility of the gas. Because the amount of water that can be pumped through an aquifer is determined by the hydrogeological characteristics and the number of injection and recovery wells that can economically be placed at a contaminated site, gas dissolution devices that generate high levels of dissolved gas concentrations are desirable.

\subsection{OBJECTIVES}

The primary objective of this project is to demonstrate the ability of hydrogen to supply reducing equivalents for the reductive dehalogenation of PCE. This objective will be accomplished by two types of activities. First, laboratory experiments will compare the kinetics of hydrogen-mediated dehalogenation with natural routes of loss (hydrolysis and natural attenuation). Secondly, bench-scale column experiments will be performed to demonstrate hydrogen-mediated reductive dehalogenation in aquifer sediments.

\subsection{ACCOMPLISHMENTS/WORK PERFORMED}

\subsection{Analytical Methods}

\subsubsection{Gas Chromatography - Electron Capture Method}

Standards for PCE, 99.9\% were made using methanol as a solvent for the analysis of PCE concentrations in column influent and effluent. 1,2,3-trichloropropane (TCP), 99\% were used as an internal standard. Syringes were rinsed with methanol after each use and a 1- $\mu \mathrm{L}$ sample of methanol was injected into the gas chromatograph (GC) as a check on cross contamination. Isothermal analyses were performed on a Shimadzu GC-17A equipped with a $\mathrm{Ni}^{63}$ electron capture detector. The column is $30 \mathrm{~m}$ long and has an inside diameter of $0.32 \mathrm{~mm}$ with a phase thickness of $0.5 \mu \mathrm{m}$. Ultrapure nitrogen was used as the carrier gas. A split ratio of 65:1 and column flow of $1.2 \mathrm{~mL} / \mathrm{min}$ were maintained. Injector and detector temperatures were set to $250^{\circ} \mathrm{C}$.

Concentrations for the PCE standards were $50,100,250,500$, and $750 \mu \mathrm{g} / \mathrm{L}$. One and onehalf $\mathrm{mL}$ of each PCE standard was mixed with $0.5 \mathrm{~mL}$ of $100-\mathrm{mg} / \mathrm{L}$ TCP in $2-\mathrm{mL}$ clear vials with silicone septa screw tops. One $\mu \mathrm{L}$ was removed from the standard sample and analyzed using the GC. An interference peak representing methanol occurred at approximately $2.3 \mathrm{~min}$, followed by the PCE peak at 3.4 min and the TCP internal standard peak at $4.8 \mathrm{~min}$. The results were repeatable (see Figure 1). 


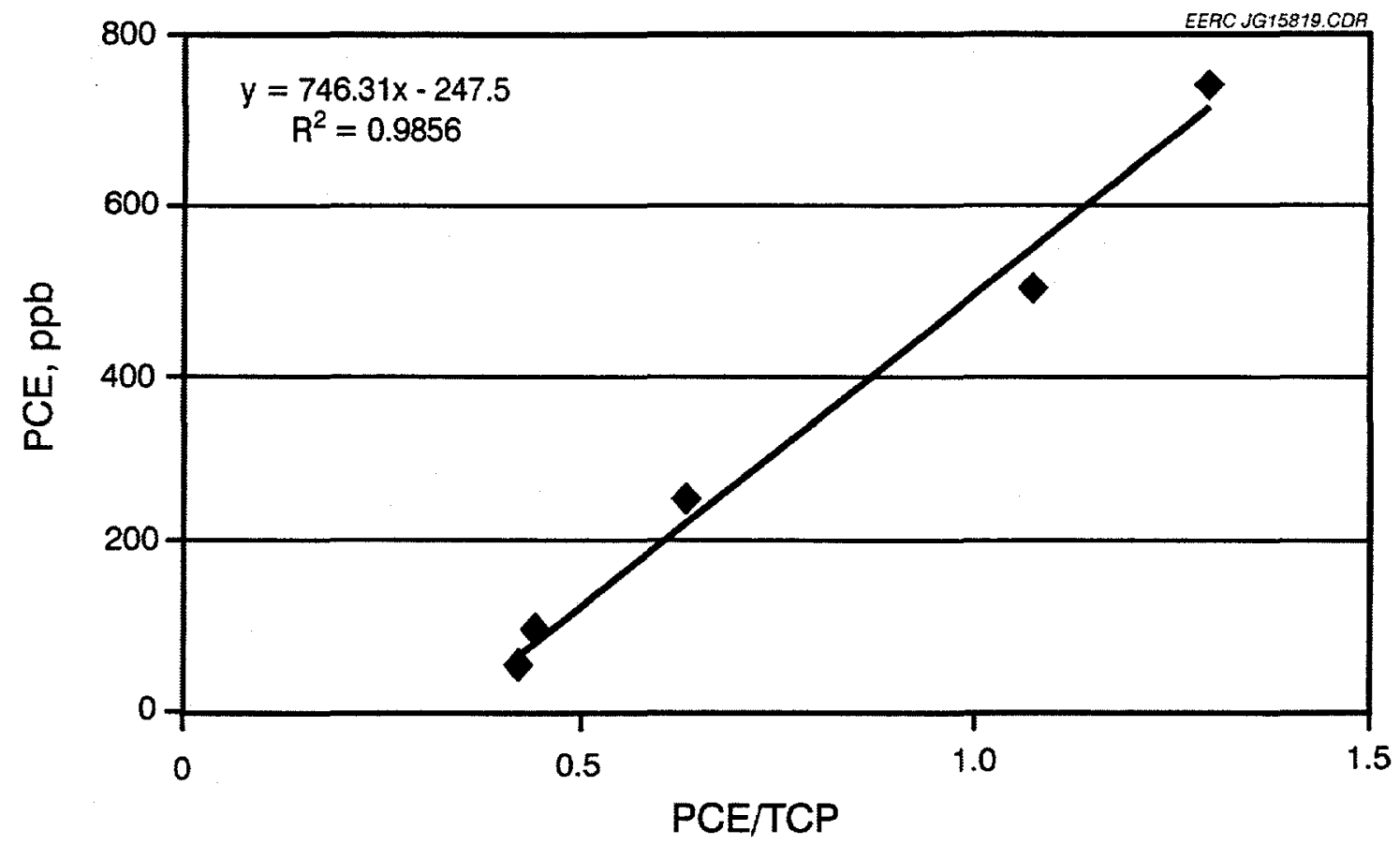

Figure 1. Example calibration curve for PCE using TCP as the internal standard and GC with electron capture detection.

\subsubsection{Gas Chromatography - Flame Ionization Method}

Samples for analysis of chlorinated aliphatic hydrocarbons (CAHs) were withdrawn from a septum on each aquifer simulator with a syringe. This aliquot was injected into a small vial containing the internal standard, methyl tertiary-butyl ether (MTBE). The contents of this vial were mixed and a sample withdrawn from it using solid-phase microextractors (SPME) and injected into the gas chromatograph. The GC was performed using an HP 5890 with a $100-\mathrm{m} \times$ $0.25-\mathrm{mm}$ Petrocol $\mathrm{DH}$ column (0.5- $\mu \mathrm{m}$ phase thickness). The carrier gas was hydrogen at $1.0 \mathrm{~mL} / \mathrm{min}$, measured at $330^{\circ} \mathrm{C}$. Split injections were used, and the detector was flame ionization (FID). The oven temperature was $35^{\circ} \mathrm{C}$ at the injector; Rate $\mathrm{A}$ was $5^{\circ} \mathrm{C} / \mathrm{min}$ to $160^{\circ} \mathrm{C}$; and Rate B was $50^{\circ} \mathrm{C} / \mathrm{min}$ to $300^{\circ} \mathrm{C}$. The total run time was 29 minutes. This method has allowed for separation and a determination of the concentrations of PCE, TCE, cisdichloroethylene (cis-DCE), trans-dichloroethylene (trans-DCE), and vinyl chloride (VC).

\subsubsection{Aquifer Simulators}

Samples from the aquifer simulators were removed from the influent and effluents of the simulators using a gas-tight syringe. One $\mathrm{mL}$ of the column water was injected into a $2-\mathrm{mL}$ vial that contained the internal standard. The contents of this vial were mixed, then an aliquot was removed and analyzed by GC. Higher concentrations of PCE and metabolites (equal to or greater than $1 \mathrm{mg} / \mathrm{L}$ ) were analyzed for using GC with FID. Samples with low concentrations of PCE and metabolites were analyzed for by $\mathrm{GC}$ with electron capture detection. 


\subsubsection{Batch Samples}

Batch experiments were performed in borosilicate serum bottles sealed with Teflon Miniert ${ }^{\circledR}$ valves. For analysis, an aliquot was withdrawn from the appropriate bottle with a syringe and injected into a $2-\mathrm{mL}$ vial containing the internal standard MTBE. Analysis was done with SPME and GC as described above.

\subsubsection{Precision and Accuracy}

A solution containing $75 \mathrm{mg} / \mathrm{L}$ of PCE was prepared and injected into the gas chromatograph five times in the same manner as used for other analyses. The results of this showed a mean PCE concentration of $73.4 \mathrm{mg} / \mathrm{L}$, with a standard deviation of $3.2 \mathrm{mg} / \mathrm{L}$ and a coefficient of variation of $4.36 \%$. This indicates that the analysis is quite accurate.

\subsection{Sediment Characterization}

The sediment selected for these experiments was chosen to represent a high-conductivity aquifer. It is a sandy loam from Roeder, North Dakota, a pristine aquifer located approximately 20 miles southeast of Grand Forks, North Dakota. This deposit is a deltaic aquifer located at the western edge of the Red River Valley, near the beachline of the former glacial Lake Agassiz. The sediment is a medium, subrounded, well-sorted sand with a low clay and organic matter content. There is no evidence for calcareous minerals. Approximately $70 \%$ of the sediment is composed of quartz, about $25 \%$ a mixture of quartz and feldspar, and the remainder a mixture of shale, hornblende, and miscellaneous minerals.

\subsection{Sediment Sorption}

Tests were performed to evaluate the ability of a sediment to adsorb PCE from the dissolved phase in distilled water. The tests were performed by adding different aliquots of the selected sediment to $50 \mathrm{~mL}$ of distilled water in a $60-\mathrm{mL}$ vial sealed with a Teflon ${ }^{\mathrm{TM}}$ stopper. PCE was then added to each bottle to achieve a concentration of $120 \mathrm{mg} / \mathrm{L}$ and was allowed to equilibrate on a stir-plate for 24 hours. A $1-\mathrm{mL}$ sample was then removed from the bottles and added to a 2-mL vial containing $1 \mathrm{~mL}$ of water with MTBE as an internal standard. A $2-\mu$ Lsample from the vial was then injected into a gas chromatograph to determine the internal standard-to- contaminant area ratio. Gas chromatography was performed as described above for FID. The results of each sample were then compared to a calibration curve previously constructed to determine the dissolved-phase concentration of PCE remaining in each bottle, which in turn was used to calculate the amount of PCE sorbed to the sediment.

The data from these tests show that the sorption of PCE onto the Roeder sediment did not fit a Freundlich equation. The sorption of PCE with this sediment is low and resembles a partitioning rather than sorption, as seen by the linear relationship shown in Figure 2. 


\subsection{Aquifer Simulators}

The two aquifer simulators were operated in separate loops with a pumping rate set to approximate natural flows in the subsurface. One of the loops had hydrogen gas (prepurified) added to the headspace of the reservoir. Analysis of the PCE concentrations in the circulating water of the two columns was performed as described above. The results of these analyses to date showed that the column with added hydrogen had a faster rate of PCE loss than the control column.

The control column was designed to correct for expected losses of PCE in the aquifer simulator tests. These expected losses are due to volatilization, hydrolysis, and reductive dechlorination mediated by natural organic matter present in the sediment (natural attentuation). Of the possible mechanisms for losses of PCE in the control column, it was expected that natural attenuation would be by far the most significant. It was expected that the loss of PCE due to hydrogen-mediated dechlorination would be faster and more complete, and this was, in fact, observed. However, the observed rates were not as rapid nor as clear as expected, as shown in Figure 3. This might have resulted for several reasons. On the basis of results of the batch experiments, we found that PCE concentrations of $150 \mathrm{mg} / \mathrm{L}$ and potentially much lower were toxic to microbial activity. The aquifer simulation columns were initially operated with saturating levels of PCE, in excess of $150 \mathrm{mg} / \mathrm{L}$. In addition, because of the known partioning properties of

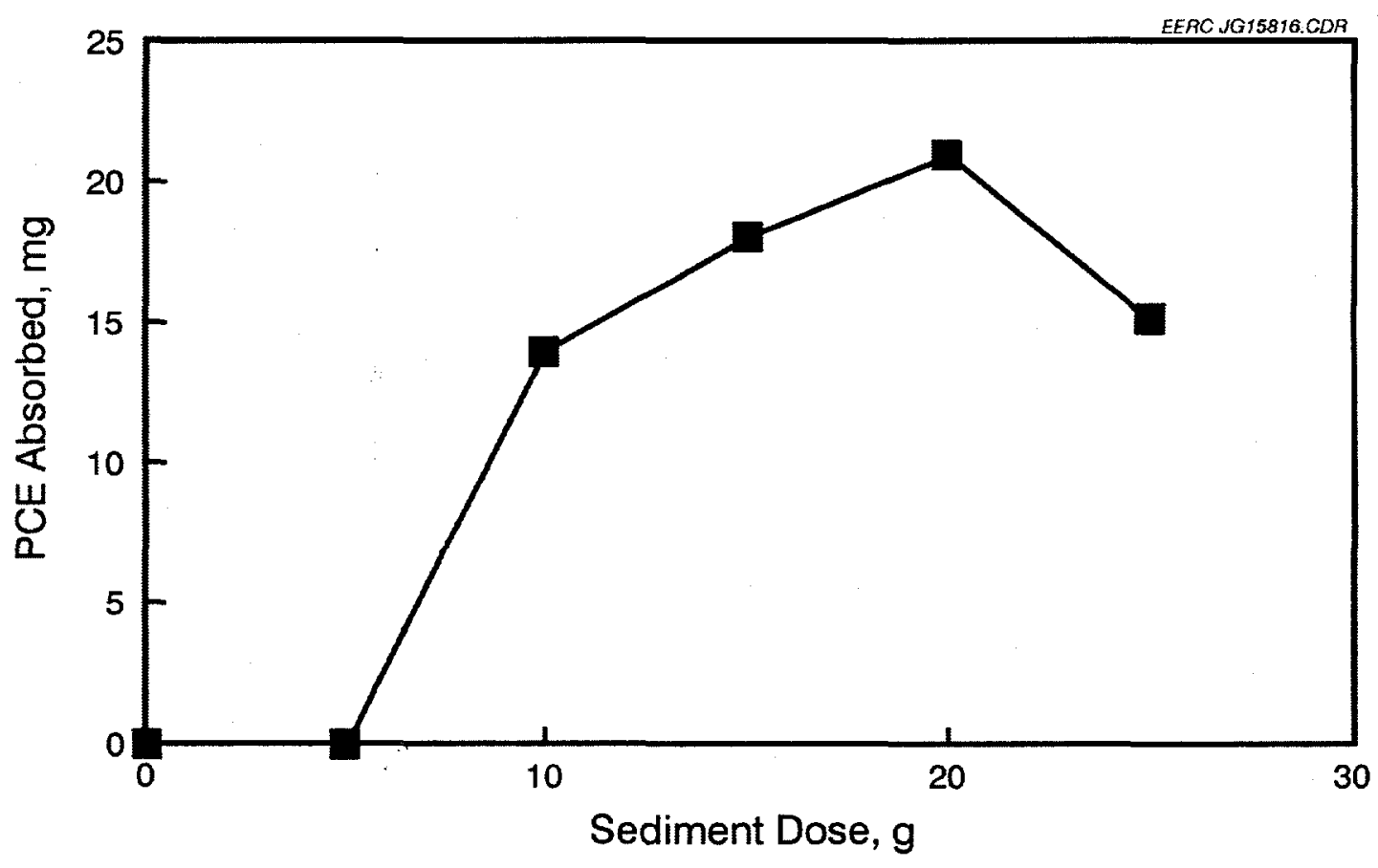

Figure 2. Sorption or partitioning of PCE into sediment from Roeder, North Dakota. 


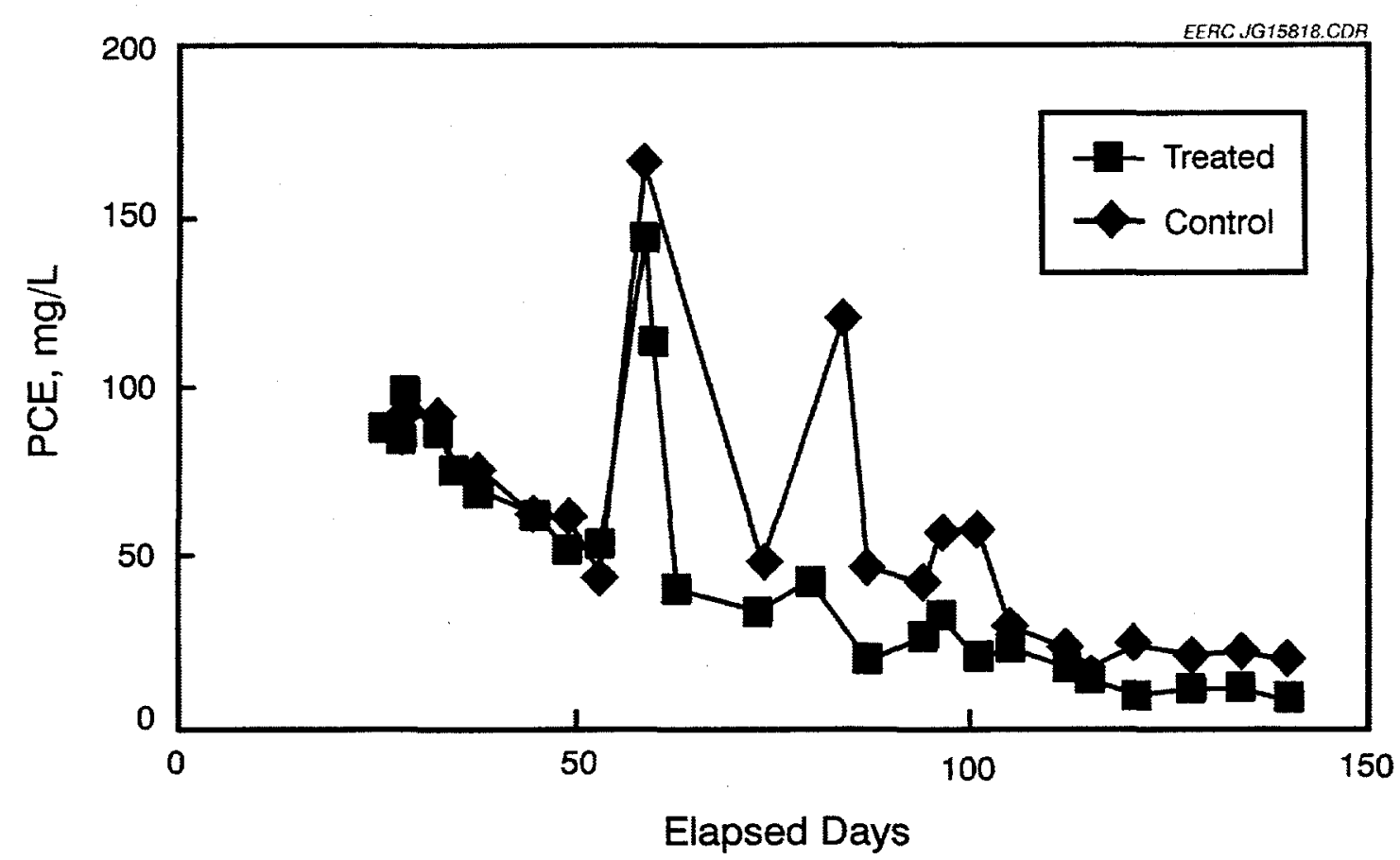

Figure 3. Comparison of effluent PCE concentrations in the treated and untreated aquifer simulators at the higher PCE loading $(100 \mathrm{mg} / \mathrm{L}$ in the influent). These data represent pseudo steady-state operation of the two simulators from September 1997 through February of 1998.

PCE, much higher concentrations occur on the surface of the sediment particles, in the same area where the microorganisms reside. As a result, we were concerned that the performance of hydrogen-mediated dechlorination observed was not optimal.

To address this concern, in early February 1997, the operation of columns was changed. Only a single column, the one that had hydrogen added, was used and operated in a flow-through mode. The pumping rate was set to $4 \mathrm{~mL} / \mathrm{min}$ to give a residence time of approximately 2 days. The solution pumped through this column was distilled water with $1 \mathrm{~g} / \mathrm{L}$ sodium bicarbonate to provide buffering and simulate natural groundwater composition and $10 \mathrm{mg} / \mathrm{L}$ PCE. The dosed water was added to the bottom of the column, and the hydrogen was introduced in the same location via a port equipped with a Teflon ${ }^{\mathrm{TM}}$-faced rubber septum. The introduced water flows past the bubble of hydrogen in the column, dissolving and transporting it into the column. Analysis for PCE and metabolites in this mode of operation showed that PCE was significantly reduced, but the amount of reduction was not much above that expected for natural attenuation. At no time during these operations were any known intermediates or metabolites detected in the GC analyses. These metabolites may have been completely reduced to ethylene (not detected in this method), sorbed to the sediment, or present below the detection limit. The metabolites would probably sorb to the sediment somewhat better than PCE, based on changes in aqueous solubility. 
It was suspected that toxicity of PCE was still a problem, therefore the concentration of PCE in the feed was reduced to $1 \mathrm{mg} / \mathrm{L}(1000 \mu \mathrm{g} / \mathrm{L})$. The column was operated with this feed for about 6 months. Additionally, to ensure that the sediment in the column was bioactive, on three occasions $1 \mathrm{~L}$ of water was added that had $1 \mathrm{~g} / \mathrm{L}$ of potassium phosphate, $1 \mathrm{~g} / \mathrm{L}$ of ammonium sulfate, and $1 \mathrm{~g} / \mathrm{L}$ of glucose. When the column appeared to be in pseudo steady state, on the basis of length of time operating under the new conditions and some analytical data, a series of PCE analyses was performed. The results of these analyses are shown in Figure 4.

The data in Figure 4 show that the simulator influent had a mean concentration of $1409 \mathrm{ppb}$ with a standard deviation of $144 \mathrm{ppb}$ and a mean effluent concentration of $838 \mathrm{ppb}$ with a standard deviation of $79 \mathrm{ppb}$. This represents a mean decrease in PCE of $570 \mathrm{ppb}$. This appears to be highly significant, as the column is relatively small to have the capacity for the observed level of reduction. In addition, many sites are contaminated with PCE at much lower levels, around 100 or $200 \mathrm{ppb}$, suggesting that this technology has the capability to remediate PCE completely at these concentrations. It might have been desirable to test the aquifer simulator at these lower concentrations; however, in the laboratory it is difficult to maintain constant concentrations this low in the feed, and the analytical difficulties become larger, as well.

\subsection{FUTURE WORK}

This task was completed in this quarter; however, we plan to look for additional funding from other sources to conduct further research and to do a demonstration project.

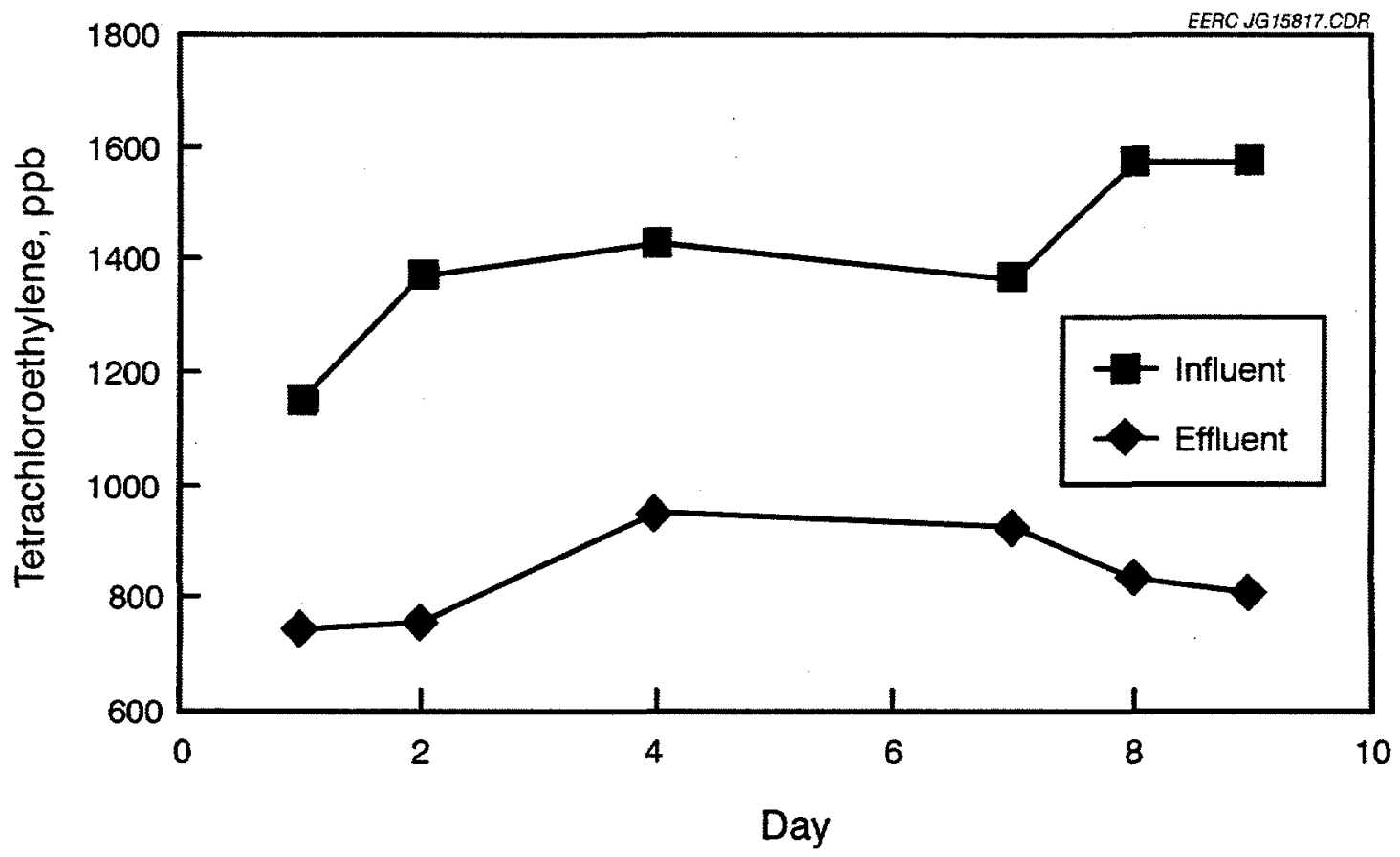

Figure 4. Influent and effluent PCE concentrations from the flow-through aquifer simulator using hydrogen-mediated biological treatment during pseudo steady state. 